\title{
High Levels of Circulating Cytomegalovirus DNA Reflect Visceral Organ Disease in Viremic Immunosuppressed Patients Other Than Marrow Recipients
}

Robin L. Saltzman, ** Mary R. Quirk, * and M. Colin Jordan *s

Division of Infectious Diseases, *Departments of Medicine and ${ }^{\S}$ Microbiology, University of Minnesota Medical School, Minneapolis, Minnesota 55455; and ${ }^{\ddagger}$ Metropolitan Mt. Sinai Medical Center, Minneapolis, Minnesota 55455

\begin{abstract}
Although viremia is a hallmark of disseminated cytomegalovirus (CMV) infection, not all viremic patients have visceral organ CMV disease. We used blot hybridization with a cloned subgenomic probe to quantitate viral DNA in blood leukocytes of 60 viremic patients ( 25 with solid organ transplants, 20 with AIDS, and 15 marrow recipients) who had different clinical manifestations of CMV infection. The results are expressed as pg of viral DNA / $10 \mu \mathrm{g}$ of leukocyte DNA. Patients with AIDS or with solid organ transplants who had CMV visceral organ disease had the largest amounts of viral DNA in their granulocytes (median 632 and $237 \mathrm{pg}$, respectively). These amounts were significantly greater than those in similar viremic patients without CMV visceral disease (17 and $21 \mathrm{pg} ; P<0.005$ and 0.002 , respectively). All patients in the study with $>150 \mathrm{pg}$ of CMV DNA in their granulocytes had visceral CMV disease. The amounts of viral DNA in granulocytes of AIDS and organ transplant patients with CMV retinitis were low (median 22 pg). Marrow transplant patients were unique in that the amounts of CMV DNA in granulocytes were low whether CMV visceral organ disease was present (17 pg) or absent (14 pg). We conclude that high levels of circulating CMV DNA in viremic AIDS and solid organ transplant patients reflect viral involvement of visceral organs but not the retina. In marrow recipients, the severity of CMV disease, even when fatal, is not reflected quantitatively in peripheral blood leukocytes. ( $J$. Clin. Invest. 1992. 90:1832-1838.) Key words: AIDS • transplantation • granulocytes $\bullet$ interstitial pneumonia
\end{abstract}

\section{Introduction}

Disseminated cytomegalovirus (CMV) ${ }^{1}$ infections occur frequently in immunocompromised patients, particularly in those with AIDS and in recipients of solid organ or bone

This work was presented in part at the National Meeting of the American Society for Clinical Investigation, Washington, DC, May 1990 (1990. Clin. Res. 38:461A).

Dr. Saltzman's current address is Bristol-Myers Squibb Pharmaceutical Research Institute, P.O. Box 4000, Princeton, NJ 08543.

Address correspondence and reprint requests to Dr. Jordan, Box 250, University of Minnesota Hospital and Clinics, 516 Delaware St. S.E., Minneapolis, MN 55455.

Received for publication 27 January 1992 and in revised form 1 June 1992.

1. Abbreviation used in this paper: $\mathrm{CMV}$, cytomegalovirus.

J. Clin. Invest.

(C) The American Society for Clinical Investigation, Inc.

$0021-9738 / 92 / 11 / 1832 / 07 \$ 2.00$

Volume 90, November 1992, 1832-1838 marrow grafts $(1-7)$. The virus can be recovered in culture from the peripheral blood leukocytes of most patients with CMV disease. In the majority of cases, CMV has been recovered from granulocytes and much less frequently from mononuclear cells (8-13). More recently, recombinant DNA techniques have been used to study CMV viremia (14-16). We have previously demonstrated that granulocytes of viremic patients contain significantly larger quantities of CMV DNA than do the mononuclear cells (16). However, the differences are not strictly quantitative. Mononuclear cells usually do not release infectious virus in culture even when they contain amounts of CMV DNA similar to those detected in simultaneously collected granulocytes that are culture positive. Using in situ DNA hybridization, Turtinen et al. (17) and Dankner et al. (18) have shown that monocytes are the predominant, if not the only, mononuclear cells which contain CMV DNA during viremia.

Reports have appeared indicating that not all immunosuppressed patients with CMV viremia develop disease. Zaia et al. (10) studied 18 marrow transplant patients with CMV viremia that was detected in routine surveillance cultures obtained at specified intervals. Only seven of the patients developed CMV pneumonitis. However, in more recent studies, the rates of interstitial pneumonia in viremic marrow recipients have ranged from 60 to $70 \%(19,20)$. In this report, we present studies in which the amounts of CMV DNA in peripheral blood leukocytes of viremic patients have been quantitated by DNA blot hybridization. Patients with diverse underlying conditions and with different manifestations of CMV disease were studied. The results indicate that there are major quantitative differences in the amounts of viral DNA in leukocytes of patients who are immunocompromised for different reasons. In addition, large quantities of circulating CMV DNA in granulocytes correlate strongly with the presence of visceral organ disease caused by the virus in solid organ transplant recipients and in patients with AIDS, but not in marrow recipients.

\section{Methods}

Patients. Blood samples were obtained from 60 immunocompromised patients. In each case, CMV had been recovered from peripheral blood granulocytes in the University of Minnesota Clinical Virology Laboratory. Additional blood for the CMV DNA hybridization studies was obtained within 1-3 d of the initial detection of CMV viremia. None of the patients was receiving antiviral therapy with ganciclovir or foscarnet at the time the blood samples were obtained. As noted subsequently, certain marrow transplant recipients had received acyclovir, immunoglobulin, or both, prophylactically or therapeutically for varying periods (see Results). None of the solid organ transplant or AIDS patients was receiving acyclovir or immunoglobulin when blood samples were obtained.

The underlying immunosuppressive states of the viremic patients in the study were solid organ transplantation in 25, AIDS in 20, and bone marrow transplantation in 15 . Among the 60 patients, 24 had clinically apparent visceral organ involvement with CMV, which was 
documented by viral culture and by the presence of the characteristic intranuclear inclusions in tissues obtained by biopsy or at autopsy or in cells present in the bronchoalveolar lavage fluid of patients with interstitial pneumonitis. The remaining 36 patients had no localizing clinical evidence of significant visceral organ involvement with CMV. This group included 7 patients with typical CMV retinitis and 29 patients who had positive CMV blood cultures obtained during a febrile illness. Thus, all patients in the study were suspected of having active CMV infection, and none of the blood samples were obtained for routine surveillance purposes. Leukocyte samples were also obtained from healthy CMV-seronegative adults for use as negative controls in the viral DNA studies.

Laboratory studies. Before extraction of viral DNA from leukocytes, the cell populations were enriched into polymorphonuclear and mononuclear leukocytes using Ficoll-Hypaque (16). Aliquots of separated leukocytes were washed in phosphate-buffered saline, pelleted by low-speed centrifugation, and stored at $-70^{\circ} \mathrm{C}$ for subsequent extraction of DNA.

DNA was extracted from the leukocyte populations in phenol, chloroform, and isoamyl alcohol and was precipitated in ethanol as described previously $(16,21)$. For detection of CMV DNA in leukocytes by blot hybridization, the XbaI subgenomic fragment " $C$ " of the Towne strain of $\mathrm{CMV}$ was used as the probe. The fragment was radiolabeled by nick translation using [ $\left.{ }^{32} \mathrm{P}\right]$ deoxycytidine triphosphate as described by Rigby et al. (22). The specific activity of the probe in different experiments was $1-3 \times 10^{8}$ counts/min per $\mu \mathrm{g}$ of DNA. The procedure used to quantitate the amount of CMV DNA contained within leukocyte cellular DNA has been described in detail (21). Briefly, $10 \mu \mathrm{g}$ of denatured DNA from peripheral blood leukocytes were spotted onto nylon membranes (Zeta-Probe, Bio-Rad Laboratories; Richmond, CA). The membranes were then washed, air dried, and baked at $80^{\circ} \mathrm{C}$ for $2 \mathrm{~h}$. After prehybridization, the membrane was transferred to the hybridization solution containing the denatured radiolabeled CMV probe. Hybridization was carried out at $68^{\circ}$ for $12-24 \mathrm{~h}$. After further washing in increasingly stringent solutions, radiolabeled hybrid DNA molecules were detected by autoradiography using XAR5 film (Eastman Kodak Co., Rochester, NY) and two intensifying screens at $-70^{\circ} \mathrm{C}$. In addition to the patient samples and negative controls, each blot contained positive standards consisting of known amounts of CMV DNA diluted sequentially in $10 \mu \mathrm{g}$ pooled human leukocyte DNA obtained from four healthy adults seronegative for CMV. An optical scanning system composed of a videocamera, a videodigitizing circuit, and a microcomputer assigned optical density values to these positive standards, allowing the establishment of a standard curve. Linear-regression analysis was then applied to the dilutions of the positive standards, and the amount of CMV DNA in leukocytes was derived after the optical density of each sample was determined (21). The results are expressed as pg of CMV DNA/10 $\mu \mathrm{g}$ of host leukocyte DNA. This amount of leukocyte DNA is equivalent to $\sim 1 \times 10^{6}$ cells.

Statistical analysis. Because of an extremely broad range in the amounts of CMV DNA detected in leukocytes of some subsets of patients, we used median rather than mean values for statistical analysis. In addition, neither the raw data nor logarithmically transformed data were normally distributed. Hence, a rank test was used for analysis (Wilcoxon-Mann-Whitney for comparing two groups and Kruskal Wallis for more than two groups) (23). $P$ values $<0.05$ were considered statistically significant.

\section{Results}

The overall results of quantitation of the CMV DNA detected in the two populations of leukocytes obtained from all 60 viremic patients are summarized in Table I. No statistically significant differences in the median amounts of CMV DNA were found in granulocytes of the three groups. However, the median amounts of CMV DNA detected in mononuclear cells of viremic patients with AIDS and in solid organ transplant recipi-
Table I. Quantity of CMV DNA in Leukocytes of Viremic Patients with Different Underlying Immunosuppressive Conditions

\begin{tabular}{clcl}
\hline Cell type & \multicolumn{1}{c}{ Underlying state } & Median & \multicolumn{1}{c}{ Range } \\
\hline Granulocyte & AIDS $(n=20)$ & 24 & $(0-80,000)$ \\
& Solid organ transplant $(n=25)$ & 38 & $(0-1,476)$ \\
& Bone marrow transplant $(n=15)$ & 19 & $(0-99)$ \\
Mononuclear & AIDS & $35^{*}$ & $(0-3,800)$ \\
& Solid organ transplant & $31^{*}$ & $(0-277)$ \\
& Bone marrow transplant & 15 & $(0-52)$ \\
\hline
\end{tabular}

${ }^{*} P<0.01$ for comparison with bone marrow transplant patients.

ents were significantly higher than in marrow recipients $(P$ $<0.01$ ).

We also determined whether there were significant differences in the amounts of CMV DNA in the two leukocyte populations of all patients when the specific clinical manifestations of the CMV infection were taken into account. The clinical presentations analyzed included visceral organ disease (pneumonitis, hepatitis, esophagitis, gastritis, or colitis), viremia in the absence of visceral involvement, and retinitis (Table II). The median quantity of CMV DNA in granulocytes of patients with visceral organ disease was significantly greater than that in viremia or chorioretinitis $(P<0.003)$. In addition, the amount of CMV DNA in mononuclear cells of patients with visceral disease was significantly greater than that in patients with viremia alone $(P<0.03)$.

Further analysis of the subgroups of viremic patients yielded several differences that were highly significant statistically. Individual data points for each patient catagorized by underlying immunosuppressive state and by clinical manifestations of the CMV infection are shown in Fig. 1. The median values for the amounts of CMV DNA detected in leukocytes of each patient population are also included. By far, the largest amounts of CMV DNA were detected in granulocytes of patients with AIDS who had clinically apparent visceral organ disease due to CMV. This difference was highly significant compared with AIDS patients lacking visceral organ involvement $(P<0.005)$ or marrow recipients with or without CMV organ involvement $(P<0.002$ and $P<0.001$, respectively). AIDS patients with visceral organ involvement due to CMV also tended to have larger amounts of circulating viral DNA in granulocytes (median $632 \mathrm{pg}$ ) than solid organ transplant recipients with visceral disease (median $237 \mathrm{pg}$ ), but this difference

Table II. Quantity of CMV DNA in Leukocytes of Viremic Patients with Different Manifestations of CMV Infection

\begin{tabular}{llcl}
\hline \multicolumn{1}{c}{ Cell type } & \multicolumn{1}{c}{ CMV manifestation } & Median & \multicolumn{1}{c}{ Range } \\
\hline Granulocyte & Visceral disease $(n=24)$ & $187^{*}$ & $(0-80,000)$ \\
& Viremia only $(n=29)$ & 17 & $(0-80)$ \\
& Retinitis $(n=7)$ & 22 & $(0-75)$ \\
Mononuclear & Visceral disease & $42^{\ddagger}$ & $(0-3,800)$ \\
& Viremia only & 20 & $(0-108)$ \\
& Retinitis & 33 & $(15-70)$ \\
\hline
\end{tabular}

* $P<0.003$ for comparison with patients with viremia only or retinitis.

${ }^{\ddagger} P<0.03$ for comparison with viremia only. 


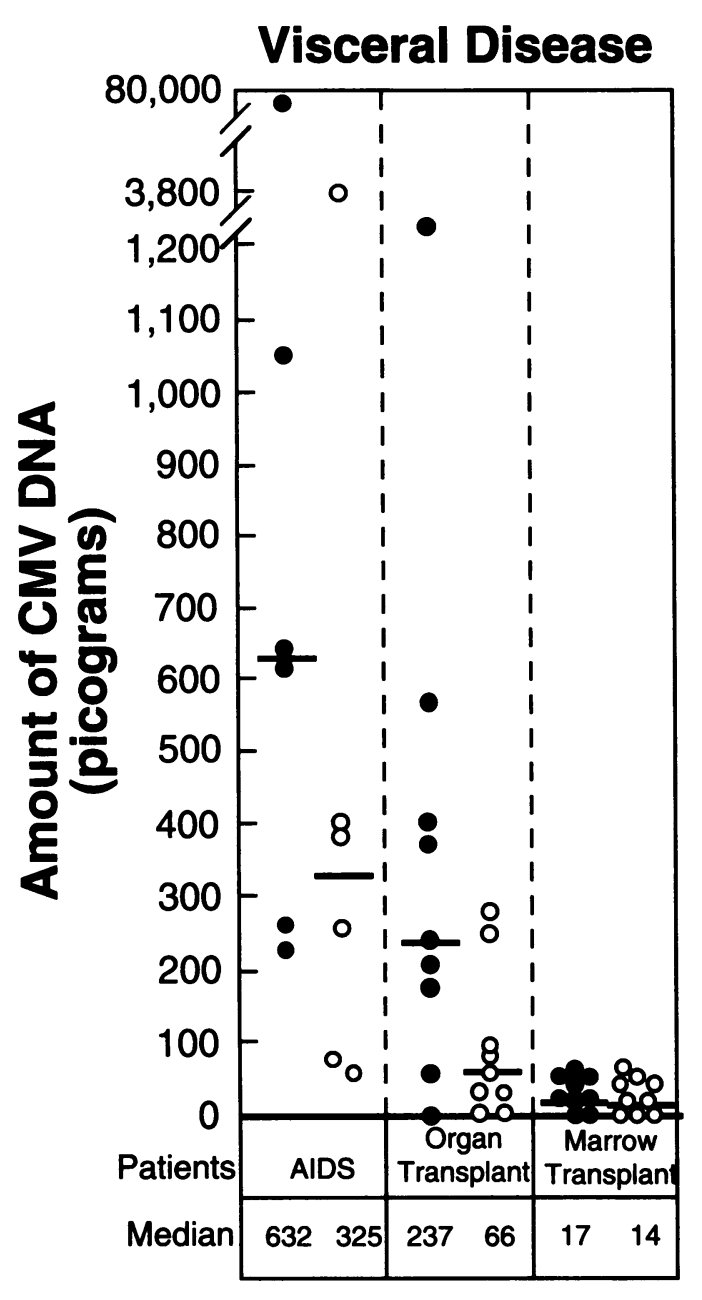

\section{Viremia Only}

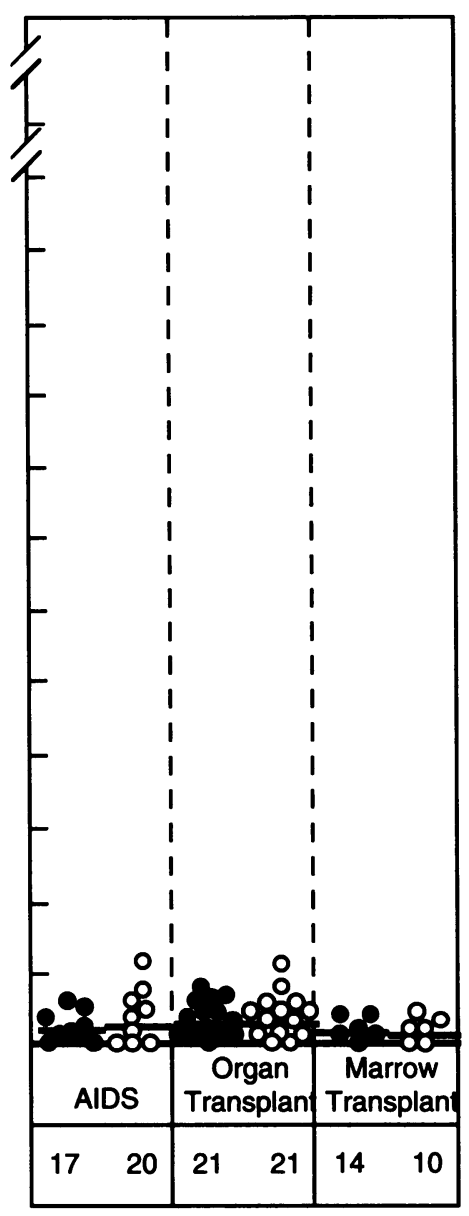

Figure 1. Amounts of CMV DNA in granulocytes (closed circles) and mononuclear cells (open circles) of patients with CMV viremia. Medians are indicated by horizontal bars. Results are expressed as pg of CMV DNA/ $10 \mu \mathrm{g}$ of host leukocyte DNA. did not reach statistical significance $(P=0.077)$. Among the solid organ transplant recipients, large amounts of CMV DNA in granulocytes also reflected visceral organ involvement due to the virus, although the difference was less impressive quantitatively compared with the patients with AIDS. Thus, the median amount of CMV DNA in granulocytes of organ recipients with visceral CMV disease $(237 \mathrm{pg})$ was $>10$-fold greater $(P$ $<0.002)$ than in their counterparts without apparent organ involvement $(21 \mathrm{pg})$.

When the data from patients with AIDS and solid organ transplant recipients were combined, the amount of CMV DNA in granulocytes of patients with visceral organ involvement exceeded $150 \mathrm{pg}$ in 13 of 15 instances. In addition, all patients in the study with $>150 \mathrm{pg}$ of viral DNA in their granulocytes had visceral organ disease due to CMV. In contrast, all of the 25 viremic AIDS or solid organ transplant patients without clinically apparent CMV visceral involvement had $<100$ pg of viral DNA in their granulocytes $(P<0.001$, Fischer's exact test).

No correlation between the amounts of CMV DNA in granulocytes and organ involvement was found in viremic marrow transplant patients. In fact, the quantity of CMV DNA detected in granulocytes of marrow recipients was virtually identical (Fig. 1) whether CMV visceral disease was present $(17 \mathrm{pg})$ or absent $(14 \mathrm{pg})$. However, interpretation of these results is confounded by the fact that 8 of the 15 marrow recipients studied had received either prophylaxis ( 4 patients) or attempted therapy ( 4 patients) with acyclovir, intravenous immunoglobulin, or both in combination. In these instances, blood samples for detection of CMV viremia and quantitation of viral DNA were obtained after or during administration of these agents for varying periods. Two of the treated patients had received only a single dose of acyclovir. Nevertheless, the amounts of circulating CMV DNA in granulocytes of the eight viremic patients who had received some antiviral therapy were virtually identical to those in the seven patients who were not treated ( 17 and $15 \mathrm{pg}$, respectively). Documented visceral organ disease due to CMV was present in five of the eight treated patients and was fatal in three. Visceral involvement was present in four of seven patients who were not treated and was fatal in all four. Because the amounts of CMV DNA detected in all of these patients were uniformly low, no significant differences could be detected whether antiviral therapy was attempted or not, or whether visceral CMV disease was present or absent.

Typical CMV retinitis was associated with viremia in seven patients, five with AIDS and two with solid organ transplants (not included in Fig. 1). The amounts of CMV DNA in the granulocytes of these patients ranged from 0 to $75 \mathrm{pg}$, with a median value of $22 \mathrm{pg}$. This amount of viral DNA is essentially identical to that found in other viremic patients lacking demonstrable visceral organ involvement (i.e., the "viremia only" groups in Fig. 1).

A similar analysis was performed for the amounts of CMV DNA detected in mononuclear cells of viremic patients with 
Table III. Frequency of Recovery Cytomegalovirus from Mononuclear Cell Cultures of Viremic Patients

\begin{tabular}{lcc}
\hline \multicolumn{1}{c}{ Patients } & $\begin{array}{c}\text { Visceral } \\
\text { disease }\end{array}$ & $\begin{array}{c}\text { Viremia } \\
\text { only }\end{array}$ \\
\hline AIDS & $3 / 6^{*}$ & $1 / 9$ \\
Solid organ recipients & $7 / 9$ & $2 / 14$ \\
Marrow recipients & $3 / 9$ & $0 / 6$ \\
Total & $13 / 24^{\dagger}$ & $3 / 29$ \\
\hline
\end{tabular}

* Number positive/number tested.

${ }^{\ddagger} P<0.01$ for comparison with patients with viremia only.

different underlying immunosuppressive states and with various clinical manifestations of the CMV infection (Fig. 1). As expected, the amounts of CMV DNA in mononuclear cells were generally lower than in granulocytes. However, the amounts of CMV DNA in mononuclear cells of AIDS patients with visceral organ involvement were significantly greater than in AIDS patients without organ involvement $(P<0.002)$, in solid organ transplant patients with or without organ involvement $(P<0.04$ and $P<0.001$, respectively), and in bone marrow recipients $(P<0.002)$. In the solid organ recipients, mononuclear cells of patients with $\mathrm{CMV}$ visceral organ disease contained significantly larger amounts of viral DNA than in patients without visceral disease $(P<0.002)$. When the data from patients with AIDS and solid organ transplants were combined, 6 of 15 patients with visceral organ involvement due to CMV had amounts of CMV DNA exceeding $150 \mathrm{pg}$ in their mononuclear cells. On the other hand, none of 25 patients without CMV visceral organ involvement had this amount of CMV DNA in mononuclear cells $(P<0.01$, Fischer's exact test). As noted above for granulocytes, the amounts of CMV DNA in mononuclear cells of marrow recipients were low whether visceral disease caused by the virus was present or absent ( $14 \mathrm{pg}$ and $10 \mathrm{pg}$, respectively).

We also determined whether recovery of CMV from mononuclear cells of viremic patients was correlated with the presence or absence of visceral organ disease due to CMV (Table III). The virus was recovered from mononuclear cells of $13 / 24$ patients with visceral CMV disease and from 3/29 patients without visceral organ involvement. This difference was highly significant statistically ( $P=0.0016$ by chi-square test with Yates correction, $P=0.0005$ without correction). When the amount of CMV DNA in granulocytes and mononuclear cells of the individual viremic patients was compared and analyzed, however, no significant trends were apparent (data not shown). In other words, the individual patients with the largest amounts of CMV DNA in granulocytes were not necessarily the same patients with large amounts of viral DNA in mononuclear cells. In addition, no clear-cut direct correlation could be found between positive cultures of mononuclear cells and large amounts of CMV DNA within the cells (data not shown).

\section{Discussion}

Currently, the significance of positive blood cultures for CMV in immunocompromised patients is not fully defined. In some reports, $\mathrm{CMV}$ viremia has been generally considered an indicator, or at least a harbinger, of serious disease (14, 24-27). However, there may have been a selection bias in these studies be- cause patients with severe manifestations of CMV infection were more likely to be tested for viremia. As viral cultures were obtained more systematically from patients at risk for serious CMV infection, it became clear that many viremic patients did not have or develop clinically apparent disease $(10,19,28-$ 30). To some extent, the consequences of CMV viremia may vary among different groups of patients. Among marrow recipients, viremia may be subclinical, although it is clearly a major risk factor for the development of interstitial pneumonitis, which is often fatal $(10,19,20,24)$. In solid organ transplant patients, viremia may not be associated with symptoms or may result in a "CMV syndrome," characterized by varying combinations of fever, musculoskeletal symptoms, leukopenia, atypical lymphocytosis, thrombocytopenia, and liver dysfunction (25-27, 29-33). However, visceral organ CMV disease may develop, most frequently in the lungs (27, 31-34). In patients with AIDS, CMV viremia appears to be slowly progressive, often resulting in severe disease $(35,36)$. Thus, in a recent study from France (37), 28 of 71 (39.5\%) patients infected with HIV had CMV viremia at the time of onset of their AIDSdefining illness. Over a subsequent mean interval of $7.7 \mathrm{mo}, 14$ of the $28(50 \%)$ developed CMV organ involvement. On the other hand, only 4 of the $43(9.3 \%)$ patients without CMV viremia at the onset of AIDS developed organ involvement over a mean follow-up period of $11.8 \mathrm{mo}$.

The present report, which provides more precise quantitative data using hybridization techniques to detect viral DNA, indicates that CMV viremia is by no means a uniform event, at least in patients with symptomatic infection. In addition, the amount of circulating viral DNA in leukocytes appears to reflect both the underlying state responsible for immunosuppression and the clinical manifestations of the CMV infection. Patients with AIDS who had documented visceral organ disease caused by CMV had extremely large amounts of viral DNA in their leukocytes, median values of 632 and 325 pg in granulocytes and mononuclear cells, respectively. A similar pattern, though less striking in quantitative terms, was seen in solid organ transplant recipients with CMV visceral organ disease. Here, the median amounts of viral DNA were 237 and $66 \mathrm{pg}$ in granulocytes and mononuclear cells, respectively. On the other hand, the amounts of CMV DNA in leukocytes of viremic AIDS and solid organ transplant patients without clinically apparent CMV visceral organ involvement were uniformly low (median values of $\leq 21 \mathrm{pg}$ ). It should be noted, however, that these patients were nevertheless febrile in association with CMV viremia, and several had leukopenia, mild liver dysfunction, or both. The significantly larger amount of CMV DNA in blood leukocytes of the patients with clinically apparent organ involvement presumably reflects more intense viral replication and associated tissue injury in visceral organs. It seems far less likely that a "high grade" viremia develops first and is then followed by visceral organ disease. In this regard, we did not encounter a single patient with large amounts of circulating CMV DNA who did not yet have clinically apparent visceral disease in this study of 60 immunosuppressed individuals. However, definitive resolution of this issue would require a prospective study in which CMV viremia is monitored quantitatively in the same patients over long periods of time without the administration of antiviral therapy.

The reasons for the large amounts of circulating CMV DNA in the leukocytes of AIDS patients with visceral organ CMV disease in this study are unknown. However, these re- 
sults are consistent with published reports indicating that, in general, both the frequency and severity of CMV disease in patients with AIDS are greater than in other immunosuppressed patients $(6,7)$. In addition to retinitis, esophagitis, colitis, and hepatitis, involvement of other organs previously thought to be infected only rarely with CMV has now been described with considerable frequency in AIDS patients. Thus, necrotizing adrenalitis, panarteritis involving large arteries of the bowel, encephalitis characterized by diffuse proliferation of glial nodules, and CMV peripheral neuritis are commonplace in patients dying of AIDS (38-45). Perhaps the most straightforward explanation for these observations is that patients with AIDS are more profoundly immunosuppressed than transplant recipients. However, as reviewed elsewhere, other mechanisms may be involved (46). CMV infection itself has immunosuppressive effects that could directly or indirectly augment HIV-induced immunological deterioration (47-50). In addition, CMV and HIV may simultaneously infect the same cells, at least in the brain and retina (51-53). In this regard, it has been demonstrated in vitro that each virus may enhance the gene expression and replication of the other (54-58). If such mechanisms are involved in the more rapid progression of disease in HIV-infected individuals who are also infected with CMV, cells in the nervous system and those of monocyte/ macrophage lineage appear to be the most likely targets $(17,18$, $51,52)$. It should be noted, however, that AIDS patients with CMV viremia and no apparent visceral organ involvement in this study did not have larger amounts of circulating CMV DNA than the other immunosuppressed patients. Thus, if CMV replication is augmented in some way in AIDS patients, it is not reflected in peripheral blood leukocytes unless visceral disease due to CMV is present.

Interestingly, CMV retinitis in five patients with AIDS and in two solid organ transplant recipients was not associated with large amounts of CMV DNA in blood leukocytes. This finding suggests that a relatively "low grade" CMV viremia is sufficient to seed the eye. In addition, the amount of CMV replication in the retina does not appear to be sufficient to produce a "high grade" secondary viremia. These findings are consistent with the clinical observation that immunosuppressed patients with CMV retinitis usually do not have clinically apparent involvement of visceral organs $(6,7,59)$. CMV retinitis may develop after visceral organ disease but no patients with this sequence of events were included in the present study.

The pathogenesis of CMV disease, particularly interstitial pneumonitis, in marrow transplant patients appears to be unique. Marrow recipients differ from other immunocompromised patients primarily because they possess an immunologically active graft, and graft-versus-host disease has been closely correlated with the occurrence of CMV interstitial pneumonitis in several studies $(19,60)$. Experimental evidence in humans and in animal models indicates that the onset and persistence of interstitial pneumonitis among marrow recipients are not related to the amount of virus replicating in the lung (6164). Thus, 9 of 10 marrow transplant patients reported by Shepp et al. (65) died of interstitial pneumonitis even though CMV was essentially eradicated from lung tissue after treatment with ganciclovir. The present study provides further evidence that the severity of CMV disease in marrow recipients is unrelated to the viral burden, at least as reflected in peripheral blood leukocytes during viremia. No correlation could be found between the amounts of circulating CMV DNA and the presence or absence of life-threatening disease involving the lungs and other organs. In fact, levels of CMV DNA were low in both granulocytes and mononuclear cells regardless of the clinical presentation. Although it is possible that in some instances replication of CMV may have been partially suppressed by suboptimal antiviral prophylaxis and therapy, this cannot be the full explanation. The amounts of CMV DNA in leukocytes of the patients who had received no antiviral agents, including four who died of CMV interstitial pneumonitis and disseminated disease, were also very low. Whether the small quantity of circulating CMV DNA in viremic marrow transplant patients is an indication of a lower level of CMV replication in the tissues compared with other immunosuppressed patients is not clear and requires further study. In this regard, we are currently quantitating the amounts of CMV DNA in cells obtained by bronchoalveolar lavage from different groups of immunosuppressed patients with CMV pneumonitis.

As in our previous report (16), both the amounts of CMV DNA and the frequency of recovery of infectious virus during viremia were significantly less in mononuclear cells than in granulocytes. Whether this difference reflects more efficient phagocytic degradation of infectious virus by monocytes or abortive nonpermissive infection by CMV in the latter cells is unknown. Transcription of the CMV "immediate-early" or alpha genes apparently occurs in both cell types $(17,18)$ but whether gene products that are normally expressed later in the cycle of viral replication are present has not been resolved. Definitive characterization of these molecular events will be necessary for a complete understanding of the virus-cell interactions involved in dissemination of CMV infection. Interestingly, CMV was recovered significantly more often from mononuclear cells of patients with CMV visceral organ disease in this study, even though no direct correlation was found between the amount of viral DNA and culture positivity.

Quantitation of CMV DNA in blood leukocytes, particularly in granulocytes, may have practical implications for diagnosis of visceral organ disease during viremia. Of the 15 viremic patients with AIDS or solid organ transplants who had visceral organ disease, 13 had $>150 \mathrm{pg}$ of CMV DNA in their granulocytes. All patients in the study with $>150 \mathrm{pg}$ of CMV DNA in their granulocytes had visceral organ involvement. On the other hand, none of the 25 viremic AIDS or solid organ transplant patients without CMV visceral disease had amounts of circulating viral DNA $>100 \mathrm{pg}$. Studies of a much larger number of immunosuppressed patients would be necessary to determine precisely the validity of using a "cutoff" value of circulating CMV DNA that could reliably identify patients with visceral disease. Simplification of the technique, particularly the need to extract DNA from cells and development of detection systems that do not involve radioisotopes, would also be necessary. However, since quantitation of viral DNA in leukocytes of marrow transplant patients with viremia would not identify the patients who have CMV visceral organ involvement, other approaches, such as determination of the numbers of infected cells in the peripheral blood or the extent of viral gene expression, should be investigated.

\section{Acknowledgments}

We thank the physicians at the University of Minnesota Hospital and Clinics who allowed us to study their transplant recipients and patients with AIDS. We also thank the personnel of the Clinical Virology Laboratory for their assistance, Dorothee Aeppli, Ph.D., for assistance with 
statistical analysis, Ms. Barbara Kringstad for collection of patient specimens, and Ms. Beth Wetak for expert assistance in preparation of the manuscript.

This work was supported by grants HL-35374, CA-21737, AM13083, HD-19937, AI-30456, and AI-72626 from the National Institutes of Health, the Metropolitan Mt. Sinai Medical Center Research and Education Fund, the Minnesota Medical Foundation, and the George Nelson Fund.

\section{References}

1. Ho, M. 1991. Cytomegalovirus: Biology and Infection. 2nd ed. Plenum Medical Book Co., New York. 440 pp.

2. Betts, R. F. 1982. Cytomegalovirus infection in transplant patients. Progr. Med. Virol. 28:44-64.

3. Dummer, J. S., A. Hardy, A. Poorsattar, and M. Ho. 1983. Early infections in kidney, heart, and liver transplant recipients on cyclosporine. Transplantation (Baltimore). 36:259-267.

4. Neiman, P. E., N. Reeves, G. Ray, N. Flournoy, K. G. Lerner, G. E. Sale, and E. D. Thomas. 1977. A prospective analysis of interstitial pneumonia and opportunistic viral infection among recipients of allogeneic bone marrow grafts. J. Infect. Dis. 136:754-767.

5. Winston, D. J., R. P. Gale, D. V. Meyer, and L. S. Young. 1979. Infectious complications of human bone marrow transplantation. Medicine (Baltimore). 58:1-31.

6. Jacobson, M. A., and J. Mills. 1988. Serious cytomegalovirus disease in the acquired immunodeficiency syndrome (AIDS). Clinical findings, diagnosis, and treatment. Ann. Intern. Med. 108:585-594.

7. Drew, W. L. 1988. Cytomegalovirus infection in patients with AIDS. $J$. Infect. Dis. 158:449-456.

8. Fiala, M., J. E. Payne, T. V. Berne, T. C. Moore, W. Henle, J. Z. Montogomerie, S. N. Chatterjee, and L. B. Guze. 1975. Epidemiology of cytomegalovirus infection after transplantation and immunosuppression. J. Infect. Dis. 132:421433.

9. Fiala, M. S., S. N. Chatterjee, S. Carson, S. Poolsawat, D. C. Heiner, A. Saxon, and L. B. Guze. 1977. Cytomegalovirus retinitis secondary to chronic viremia in phagocytic leukocytes. Am. J. Ophthalmol. 84:567-573.

10. Zaia, J. A., S. J. Forman, E. Gallagher, E. Vanderwal-Urbana, and K. G. Blume. 1984. Prolonged human cytomegalovirus viremia following bone marrow transplantation. Transplantation (Baltimore). 37:315-317.

11. Gadler, H., A. Tillegard, and C. G. Groth. 1982. Studies of cytomegalovirus infection in renal allograft recipients. Scand. J. Infect. Dis. 14:81-87.

12. Rinaldo, C. R., P. H. Black, and M. S. Hirsch. 1977. Interaction of cytomegalovirus with leukocytes from patients with mononucleosis due to cytomegalovirus. J. Infect. Dis. 136:667-678.

13. Howell, C. L., M. J. Miller, and W. J. Martin. 1979. Comparison of rates of virus isolation from leukocyte populations separated from blood by conventional and Ficoll-Paque/macrodex methods. J. Clin. Microbiol. 10:533-537.

14. Martin, D. C., D. A. Katzenstein, G. S. M. Yu, and M. C. Jordan. 1984. Cytomegalovirus viremia detected by molecular hybridization and electron microscopy. Ann. Intern. Med. 100:222-225.

15. Spector, S. A., J. A. Rua, D. H. Spector, and R. M. McMillan. 1984. Detection of human cytomegalovirus in clinical specimens by DNA-DNA hybridization. J. Infect. Dis. 150:121-126.

16. Saltzman, R. L., M. R. Quirk, and M. C. Jordan. 1988. Disseminated cytomegalovirus infection. Molecular analysis of virus and leukocyte interactions in viremia. J. Clin. Invest. 81:75-81.

17. Turtinen, L. W., R. L. Saltzman, M. C. Jordan, and A. T. Haase. 1987. Interactions of human cytomegalovirus with leukocytes in vivo. Analysis by in situ hybridization. Microb. Pathog. 3:287-297.

18. Dankner, W. M., J. A. McCutchan, D. D. Richman, K. Hirata, and S. A. Spector. 1990. Localization of human cytomegalovirus in peripheral blood leukocytes by in situ hybridization. J. Infect. Dis. 161:31-36.

19. Meyers, J. D., P. Ljungman, and L. D. Fisher. 1990. Cytomegalovirus excretion as a predictor of cytomegalovirus disease after marrow transplantation. Importance of cytomegalovirus viremia. J. Infect. Dis. 162:373-380.

20. Schmidt, G. M., D. A. Horak, J. C. Niland, S. R. Duncan, S. J. Forman, and J. A. Zaia. 1991. A randomized, controlled trial of prophylactic ganciclovir for cytomegalovirus pulmonary infection in recipients of allgeneic bone marrow transplants. N. Engl. J. Med. 324:1005-1011.

21. Saltzman, R. L., M. R. Quirk, and M. C. Jordan. 1990. Quantitation of cytomegalovirus DNA by blot hybridization in blood leukocytes of viremic patients. J. Virol. Methods. 30:67-78.

22. Rigby, P. W. J., M. Dieckmann, C. Rhodes, and P. Berg. 1977. Labeling deoxyribonucleic acid to high specific activity in vitro by nick translation with DNA polymerase I. J. Mol. Biol. 113:237-251.

23. Hollander, M., and D. A. Wolfe. 1973. Nonparametric Statistical Methods. Ist ed. John Wiley, New York. 365 pp.
24. Vilmer, E., M. C. Mazeron, C. Rabian, O. Azogui, A. Devergie, Y. Perol, and E. Gluckman. 1985. Clinical significance of cytomegalovirus viremia in bone marrow transplantation. Transplantation (Baltimore). 40:30-35.

25. Richardson, W. P., R. B. Colvin, S. H. Cheeseman, N. E. Tolkoff-Rubin, J. T. Herrin, A. B. Cosimi, A. B. Collins, M. S. Hirsch, R. T. McCluskey, P. S. Russell, et al. 1981. Glomerulopathy associated with cytomegalovirus viremia in renal allografts. $N$. Engl. J. Med. 305:57-67.

26. Cheeseman, S. H., R. H. Rubin, J. A. Stewart, N. E. Tolkoff-Rubin, A. B. Cosimi, K. Cantell, J. Gilbert, S. Winkle, J. T. Herrin, P. H. Black, et al. 1979. Controlled clinical trial of prophylactic human leukocyte interferon in renal transplantation. Effects on cytomegalovirus and herpes simplex virus infections. N. Engl. J. Med. 300:1345-1349.

27. Dummer, J. S., L. T. White, M. Ho, B. P. Griffith, R. L. Hardesty, and H. T. Bahnson. 1985. Morbidity of cytomegalovirus infection in recipients of heart or heart-lung transplants who received cyclosporine. J. Infect. Dis. 152:1182-1191.

28. Cox, F., and W. T. Hughes. 1975. Cytomegaloviremia in children with acute lymphocytic leukemia. J. Pediatr. 87:190-194.

29. Arnfred, J., C. M. Nielsen, E. S. Spencer, and H. K. Anderson. 1987. A prospective study of infection with cytomegalovirus in renal allograft recipients immunosuppressed with cyclosporine A and low dose prednisone. Scand. J. Infect. Dis. 19:297-302.

30. Metselaar, H. J., A. H. M. M. Balk, B. Mochtar, H. Rothbarth, and W. Weimar. 1990. Cytomegalovirus seronegative heart transplant recipients. Prophylactic use of anti-CMV immunoglobulin. Chest. 97:396-399.

31. Simmons, R. L., A. J. Matas, L. C. Rattazzi, H. H. Balfour, R. J. Howard, and J. S. Najarian. 1977. Clinical characteristics of lethal cytomegalovirus infection following renal transplantation. Surgery (St. Louis). 82:537-546.

32. Peterson, P. K., H. H. Balfour, S. C. Marker, D. S. Fryd, R. J. Howard, and R. L. Simmons. 1980. Cytomegalovirus disease in renal allograft recipients. A prospective study of clinical features, risk factors, and impact on renal transplantation. Medicine (Baltimore). 59:283-300.

33. Glenn, J. 1981. Cytomegalovirus infections following renal transplantations. Rev. Infect. Dis. 3:1151-1178.

34. Rubin, R. H., A. B. Cosimi, N. E. Tolkoff-Rubin, P. S. Russell, and M. S. Hirsch. 1977. Infectious disease syndromes attributable to cytomegalovirus and their significance among renal transplant recipients. Transplantation (Baltimore). 24:458-464.

35. Fiala, M., L. A. Cone, C. M. Chang, and E. S. Mocarski. 1986. Cytomegalovirus viremia increases with progressive immune deficiency in patients infected with HTLV-III. AIDS Res. 2:175-181.

36. Gerna, G., M. Parea, E. Percivalle, D. Zipeto, E. Silini, G. Barbarini, and G. Milanesi. 1990. Human cytomegalovirus viraemia in HIV-1 seropositive patients at various clinical stages of infection. AIDS (Phila.). 4:1027-1031.

37. Salmon, D., F. Lacassin, M. Harzic, C. Leport, C. Perronne, F. Bricaire, F. Brun-Vezinet, and J. L. Vilde. 1990. Predictive value of cytomegalovirus viremia for occurrence of CMV organ involvement in AIDS. J. Med. Virol. 32:160-163.

38. Welch, K., W. Finkbeiner, C. E. Alpers, W. Blumenfield, R. L. Davis, E. A. Smuckler, and J. H. Beckstead. 1984. Autopsy findings in the acquired immune deficiency syndrome. JAMA (J. Am. Med. Assoc.). 252:1152-1159.

39. Moskowitz, L., G. T. Hensley, J. C. Chan, and K. Adams. 1985. Immediate causes of death in acquired immunodeficiency syndromes. Arch. Pathol. Lab. Med. 109:735-738.

40. Reichert, C. M., T. J. O'Leary, D. L. Levens, C. R. Simrell, and A. M. Macher. 1983. Autopsy pathology in the acquired immune deficiency syndrome. Am. J. Pathol. 112:357-383.

41. Hui, A. N., M. N. Koss, and P. R. Meyer. 1984. Necropsy findings in acquired immunodeficiency syndrome. Human Pathol. 15:670-676.

42. Snider, W. D., D. M. Simpson, S. Nielsen, J. W. M. Gold, C. E. Metroka, and J. B. Posner. 1984. Neurological complications of AIDS: analysis of 50 patients. Am. J. Clin. Pathol. 82:678-682.

43. Hawley, D. A., J. F. Schaefer, and D. M. Schultz. 1983. Cytomegalovirus encephalitis in AIDS. Am. J. Clin. Pathol. 80:874-877.

44. Quinnan, G. V., H. Masur, A. H. Rook, G. Armstrong, W. R. Frederick, J. Epstein, J. F. Manischewitz, A. M. Macher, L. Jackson, J. Ames, et al. 1984. Herpes viruses infections in the acquired immune deficiency syndrome. JAMA (J. Am. Med. Assoc.). 252:72-77.

45. Shaw, G. M., M. E. Harper, B. H. Hahn, L. G. Epstein, D. C. Gajdusek, R. W. Price, B. A. Navia, C. K. Petito, C. J. O'Hara, J. E. Groopman, et al. 1985. HTLV-II infection in brains of children and adults with AIDS encephalopathy. Science (Wash. DC). 227:177-182.

46. Hirsch, M. S. 1991. Cytomegalovirus and its role in the pathogenesis of acquired immunodeficiency syndrome. Transplant. Proc. 23:1 18-121.

47. Rinaldo, C. R., W. P. Carney, B. S. Richter, P. H. Black, and M. J. Hirsch. 1980. Mechanisms of immunosuppression in cytomegaloviral mononucleosis. $J$. Infect. Dis. 141:488-495.

48. Levin, M. J., C. R. Rinaldo, P. L. Leary, J. A. Zaia, and M. J. Hirsch. 1979. Immune response to herpesvirus antigens in adults with acute cytomegaloviral mononucleosis. J. Infect. Dis. 140:851-857.

49. Carney, W. P., V. Iacoviello, and M. S. Hirsch. 1983. Functional proper- 
ties of T lymphocytes and their subsets in cytomegalovirus mononucleosis. $J$. Immunol. 130:390-393.

50. Carney, W. P., R. H. Rubin, R. A. Hoffman, W. P. Hansen, K. Healey, and M. J. Hirsch. 1981. Analysis of T lymphocyte subsets in cytomegalovirus mononucleosis. J. Immunol. 126:2114-2116.

51. Nelson, J. A., C. Reynolds-Kohler, M. B. A. Oldstone, and C. A. Wiley. 1988. HIV and HCMV coinfect brain cells in patients with AIDS. Virology. 165:286-290.

52. Pomerantz, R. J., D. R. Kuritzkes, S. M. de la Monte, T. R. Rota, A. S. Baker, D. Albert, D. H. Bor, E. L. Feldman, R. T. Schooley, and M. S. Hirsch. 1987. Infection of the retina by human immunodeficiency virus type 1. N. Engl. J. Med. 317:1643-1647.

53. Skolnik, P. E., R. J. Pomerantz, S. M. de la Monte, S. F. Lee, G. D. Hsiung, R. Y. Foos, G. M. Cowan, B. R. Kosloff, M. S. Hirsch, and J. S. Pepose 1989. Dual infection of retina with human immunodeficiency virus type 1 and cytomegalovirus. Am. J. Ophthalmol. 107:361-372.

54. Davis, M. G., S. C. Kenney, J. Kamine, J. S. Pagano, and E. S. Huang. 1987. Immediate-early gene region of human cytomegalovirus trans-activates the promoter of human immunodeficiency virus. Proc. Natl. Acad. Sci. USA. 84:8642-8646.

55. Mosca, J. D., D. P. Bednarik, N. B. K. Raj, C. A. Rosen, J. G. Sodroski, W. A. Haseltine, G. S. Hayward, and P. M. Pitha. 1987. Activation of human immunodeficiency virus by herpes virus infection. Identification of a region within the long terminal repeat that responds to a trans-acting factor encoded by herpes simplex virus 1. Proc. Natl. Acad. Sci. USA. 84:7408-7412.

56. Skolnik, P. R., B. R. Kostoff, and M. S. Hirsch. 1988. Bidirectional interactions between human immunodeficiency virus type 1 and cytomegalovirus. $J$. Infect. Dis. 157:508-514.

57. Ho, W.-Z., J. M. Harouse, R. F. Rando, E. Gonczol, A. Srinivasan, and
S. A. Plotkin. 1990. Reciprocal enhancement of gene expression and viral replication between human cytomegalovirus and human immunodeficiency virus type 1. J. Gen. Virol. 71:97-103.

58. Casareale, D., M. Fiala, C. M. Chang, L. A. Cone, and E. S. Mocarski. 1989. Cytomegalovirus enhances lysis of HIV-infected T lymphoblasts. Int. J. Cancer. 44:124-130.

59. Pollard, R. B., P. R. Egbert, J. G. Gallagher, and T. C. Merigan. 1980. Cytomegalovirus retinitis in immunosuppressed hosts. National history and effects of treatment with adenine arobinoside. Ann. Intern. Med. 93:655-664.

60. Meyers, J. D., N. Fluornoy, and E. D. Thomas. 1986. Risk factors for cytomegalovirus infection after human marrow transplantation. J. Infect. Dis 153:473-488.

61. Grundy, J. E., J. D. Shanley, and G. M. Shearer. 1985. Augmentation of graft-versus-host reaction by cytomegalovirus infection resulting in interstitial pneumonitis. Transplantation (Baltimore). 39:548-553.

62. Shanley, J. D., C. S. Via, S. O. Sharrow, and G. M. Shearer. 1987. Interstitial pneumonitis during murine cytomegalovirus infection and graft-versus-host reaction. Characterization of bronchoalveolar lavage cells. Transplantation (Baltimore). 44:658-662.

63. Shanley, J. D., C. Pomeroy, C. S. Via, and G. M. Shearer. 1988. Interstitial pneumonitis during murine cytomegalovirus infection and graft-versus-host reaction. Effect of ganciclovir therapy. J. Infect. Dis. 158:1391-1394.

64. Grundy, J. E., J. D. Shanley, and P. D. Griffiths. 1987. Is cytomegalovirus pneumonitis in transplant recipients an immunopathological condition? Lancet. ii:996-999.

65. Shepp, D. H., P. S. Dandliker, P. de Miranda, T. C. Burnett, D. M. Cederberg, L. E. Kirk, and J. D. Meyers. 1985. Activity of 9-[2-hydroxy-1-(hydroxymethyl)ethoxymethyl] guanine in the treatment of cytomegalovirus pneumonia. Ann. Intern. Med. 103:368-373. 